\title{
Influence of a Photo-Acid Generator on the Photoreactivity of a Photosensitive Polyimide Containing Epoxy Groups
}

\author{
Han Sung Yu, ${ }^{\dagger}$ Takashi Yamashita, ${ }^{\dagger}$ and Kazuyuki HorIE \\ Department of Chemistry and Biotechnology, Graduate School of Engineering, The University of Tokyo, \\ 7-3-1 Hongo, Bunkyo-ku, Tokyo 113, Japan
}

(Received January 26, 1996)

\begin{abstract}
Photochemical reactivity of a polyimide containing epoxy groups, PI(6FDA/ep-AHHFP), was studied in the presence of diphenyl-iodonium 9,10-dimethylanthracene-2-sulfonate (DIAS) as a photo-acid generator. IR spectroscopy was used for measuring the extent of ring-opening polymerization of epoxy groups, which was influenced by photoirradiation and post-cure conditions. By DIAS having an absorption band in $350-410 \mathrm{~nm}$, the irradiation time was shortened by twenty times for getting the same conversion compared to the previous case with diphenyliodonium hexafluoroarsenate $\left(\mathrm{DPI}^{-\mathrm{AsF}_{6}}\right)$. The activation energy for epoxy polymerization of PI(6FDA/ep-AHHFP) with DIAS was about $14 \mathrm{~kJ} \mathrm{~mol}^{-1}$. The kinetic chain length, $v$, per one acid in $\mathrm{PI}(6 \mathrm{FDA} / \mathrm{ep}-\mathrm{AHHFP})$ with DIAS was calculated to be about $4-31$. The reaction radius, $r_{\mathrm{R}}$, of an acid is about $8-16 \AA$ when heated for $5-40 \mathrm{~min}$ at $50-195^{\circ} \mathrm{C}$, which is about half for DPI-AsF 6 . The gel dose, $D_{0 \text { gel }}$, and contrast, $\gamma$, based on incident energy after post-cure at $100^{\circ} \mathrm{C}$ for $30 \mathrm{~min}$ are $117 \mathrm{~m} \mathrm{~J} \mathrm{~cm}^{-2}$ and 4.0 , respectively. The quantum yield for crosslinking of PI(6FDA/ep-AHHFP), $\Phi_{\text {gel }}$, was 0.084 from the characteristic curve. PI(6FDA/ep-AHHFP) containing DIAS works as a negative-tone photosensitive polyimide.

KEY WORDS Photosensitive Polyimide / Epoxy Group / Photo-Acid Generator / Chemical
\end{abstract} Amplification Reaction / Kinetic Chain Length / Reaction Range / Crosslinking Reaction /

The use of polyimides as high temperature insulators and dielectrics, coatings, adhesives, and matrices for high performance composites are well known. Studies of photosensitive polyimides have become important in recent years. Photosensitive polyimides are very attractive materials since they reduce the number of processing steps by avoiding the use of classical photoresists. ${ }^{1-4}$ However their sensitivities are still low. ${ }^{5,6}$ One strategy for the improvement of the photoreactivity of photosensitive polyimides is the utilization of long-lived active intermediates, ${ }^{7}$ and the other strategy is the elimination of charge transfer in the case of BTDA (benzophenone tetracarboxylic dianhydride)-type polyimide. The polyimides prepared from BTDA and aliphatic diamines are examples. $^{8}$ The chemical amplification concept is also useful technique for the design of highly-sensitive resist systems with high resolution, based on the acid-catalyzed crosslinking, deprotection, or depolymerization reactions. ${ }^{9,10}$ In addition, cationic polymerization is not sensitive to oxygen. The epoxy group can be polymerized with acid catalysts, so incorporation of the epoxy group into polyimides is expected to increase photoreactivity by using the chemical amplification technique.

In our previous paper, ${ }^{11}$ we reported the synthesis and photocrosslinking reactions of a polyimide containing the epoxy group, PI(6FDA/ep-AHHFP), which can be polymerized cationically during the post-cure after the UV irradiation in the presence of a photo-acid generator, diphenyliodonium hexafluoroarsenate (DPI-AsF 6 ). We analyzed its chemically-amplified photocrosslinking reactions by measuring IR spectra, change in molecular weight with GPC, and change in residual thickness of the sample films. PI(6FDA/ep-AHHFP) containing DPI-AsF ${ }_{6}$ was found to function as a negative photosensitive polyimide with high sensitivity and contrast.

\footnotetext{
† To whom correspondence should be addressed.
}

However, its photoreactivity above $300 \mathrm{~nm}$ is limited by low absorptivity of DPI-AsF ${ }_{6}$ in $300-400 \mathrm{~nm}$. One method to improve the photoreactivity above $300 \mathrm{~nm}$ is the utilization of photosensitizers. ${ }^{12-14} \mathrm{We}$ also reported that the introduction of benzophenone group into the main chain of the polyimide gives improves photoreactivity by sensitizing the photo-acid generator, DPI$\mathrm{AsF}_{6} \cdot{ }^{15}$ The other method is utilization of photo-acid generators with high absorbance above $300 \mathrm{~nm}$. In the present paper, we report the effects of diphenyliodonium 9,10-dimethylanthracene-2-sulfonate (DIAS) as a photoacid generator on the photoreactivity of PI(6FDA/epAHHFP) containing epoxy groups. The results are compared to the results with DPI-AsF ${ }_{6}$.

\section{EXPERIMENTAL}

\section{Materials}

The preparation of the polyimide, PI(6FDA/epAHHFP), was described previously. ${ }^{11}$ The chemical structure of PI(6FDA/ep-AHHFP) is shown below. Diphenyliodonium 9,10-dimethyl anthracene-2-sulfonate (DIAS) as a photo-acid generator was prepared by the method described by Naitoh et al. ${ }^{16}$ Diphenyliodonium hexafluoroarsenate (DPI-AsF ${ }_{6}$ ) as another photo-acid generator, and other materials were from commercial sources and used without further purification.

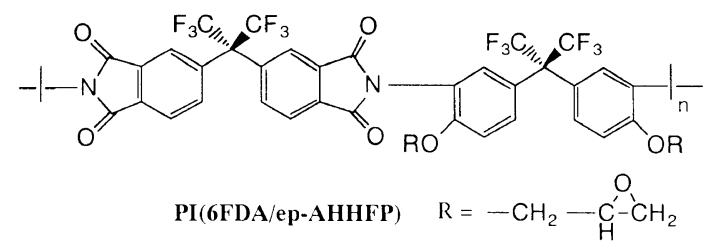

\section{Instrumentation}

IR spectra were measured with a JASCO IR-700 
spectrometer. UV absorption spectra were measured with a UVIDEC-660 spectrophotometer. Film thickness was measured using a Talistep film thickness gauge (Rank Taylor Hobson, Inc.).

\section{Photoirradiation}

Photoreaction was performed using a 450-W highpressure $\mathrm{Hg}$ lamp and glass filters (Toshiba, UVD36A and UV-33). Actinometry was carried out with a photometer (Advantest, TQ8210). The incident light intensity was $2.72 \times 10^{-9}$ einstein $\mathrm{cm}^{-2} \mathrm{~s}^{-1}$ for film thickness measurement, determination of the quantum yield for acid generation from DIAS and IR measurement.

\section{Measurements of Photoreaction}

A sample solution was prepared by dissolving PI(6FDA/ep-AHHFP) (1.0 g) and DPI-AsF ${ }_{6}(0.025 \mathrm{~g})$ or DIAS $(0.025 \mathrm{~g})$ in dichloroethane $(10 \mathrm{~mL})$, filtered through $0.2 \mu \mathrm{m}$ Teflon filter (Millipore Inc.) and transformed to thin film by casting on a glass plate. The films ( $c a .7 .5 \mu \mathrm{m}$ thick) were postbaked at various temperatures after exposure to a high-pressure Hg lamp. The reaction was monitored by the change in absorption of epoxy group at $905 \mathrm{~cm}^{-1}$ in the IR spectra calibrated by the absorption at $1510 \mathrm{~cm}^{-1}$ as an internal standard.

The film ( $c a .1 \mu \mathrm{m}$ thick), containing $5 \mathrm{wt} \%$ DIAS was prepared for the film thickness measurements, photoirradiated, and postbaked for $30 \mathrm{~min}$ in an oven at $100^{\circ} \mathrm{C}$. The films were developed with cyclohexanone for $5 \mathrm{~min}$ and rinsed with isopropyl alcohol for $3 \mathrm{~min}$.

\section{RESULTS AND DISCUSSION}

\section{Photoreaction}

It is expected that the reactivity of photo-generated acids depends not only on the nature of the materials but also on post-cure conditions. The extent of the reaction of the epoxy group during the post-cure process was measured with IR. The results are compared to those with DPI-AsF 6 .

The quantum yield of acid generation from DPI-AsF 6 in PI(6FDA/ep-AHHFP) matrix was determined to be about 0.1 at $365 \mathrm{~nm}$ using the sodium salt of resorufin as an acid indicator. ${ }^{11}$ The methodology was based on the observation by Mckean et al. ${ }^{17}$ and Naitoh et al. ${ }^{18}$ The quantum yield of acid generation from DIAS in PI(6FDA/ep-AHHFP) matrix was determined with the same method. The quantum yield of acid generation from DIAS in PI(6FDA/ep-AHHFP) was determined to be about 0.10 , which is about 1.4 times the value $(0.07)$ in PI(6FDA/AHHFP) reported by Naitoh et al. ${ }^{18}$ The difference is probably due to the presence of active hydrogens of PI(6FDA/ep-AHHFP), because acid is thought to be formed by hydrogen abstraction from the surrounding polymer.

Figure 1 shows the UV absorption spectra of DIAS and $\mathrm{DPI}-\mathrm{AsF}_{6}$ in acetonitrile solution. It is expected from Figure 1 that DIAS would have higher reactivity than DPI-AsF ${ }_{6}$ above $300 \mathrm{~nm}$, because DIAS has much larger molar absorption coefficient, $\varepsilon$, than DPI-AsF $F_{6}$. Figure 2 shows UV-spectrum of a film composed of PI(6FDA/ep-AHHFP) and DIAS. Optical density of the

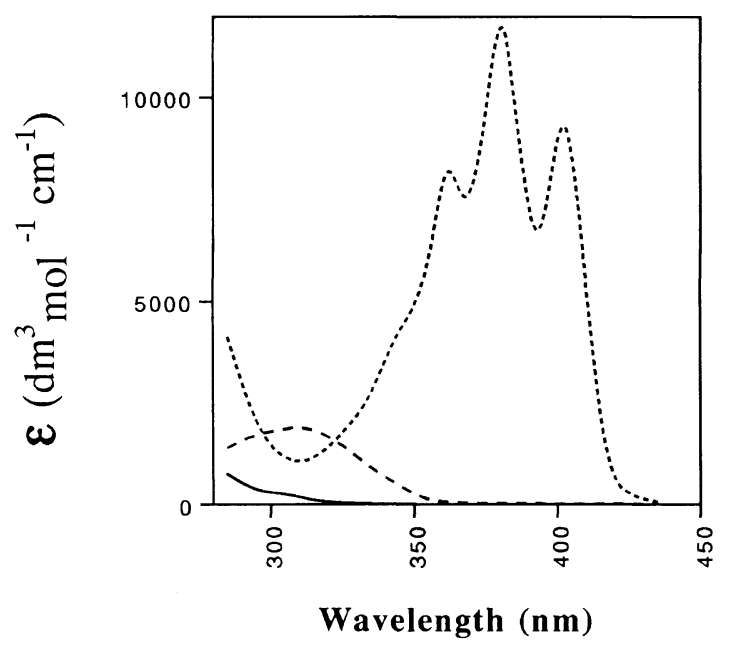

Figure 1. UV spectra of DIAS (---.-) and DPI-AsF $\mathrm{D}_{6}(-)$ in acetonitrile.

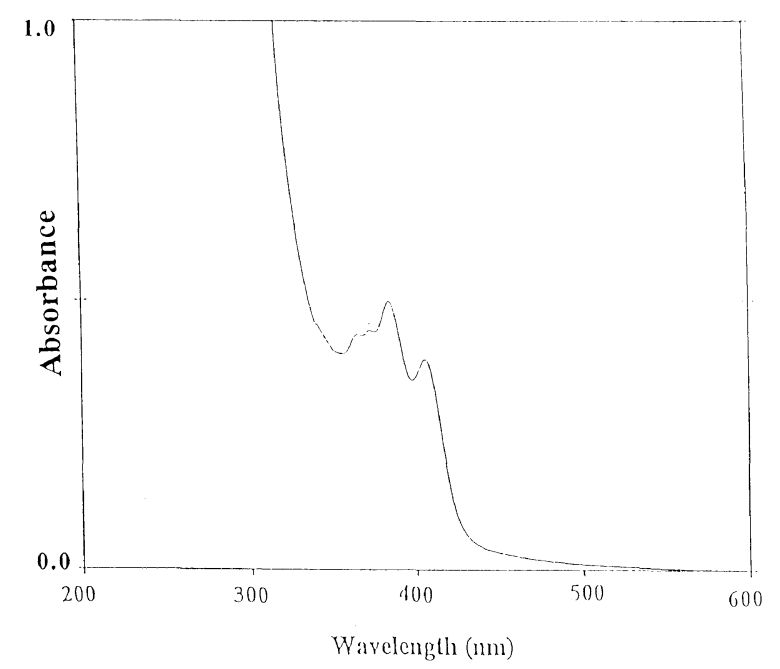

Figure 2. UV spectrum of a film composed of PI(6FDA/ep-AHHFP) and $2.5 \mathrm{wt} \%$ DIAS. (film thickness: $c a .7 .5 \mu \mathrm{m}$ ).

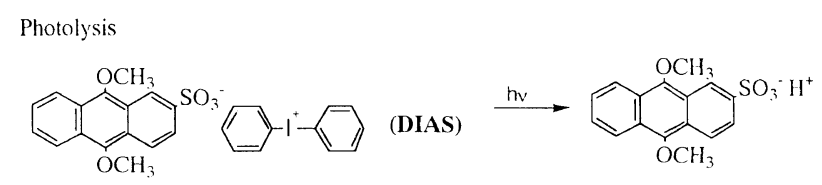

Initiation
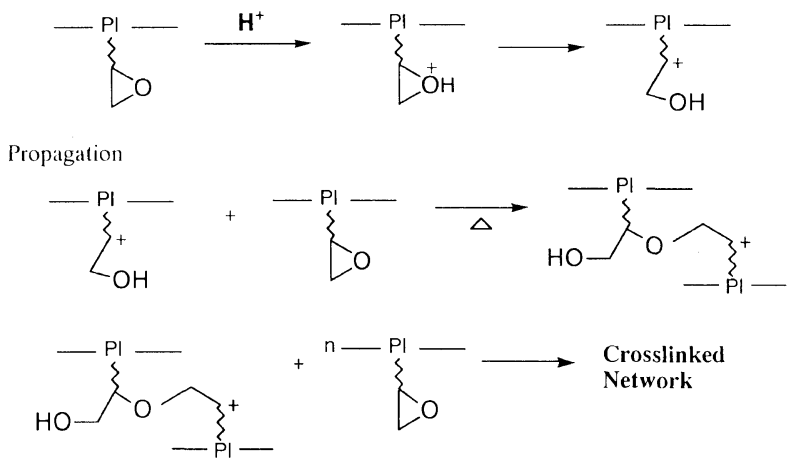

Scheme 1. Mechanism of photoreaction of PI(6FDA/ep-AHHFP).

film is less than 0.5 at $365 \mathrm{~nm}$, and the light below $330 \mathrm{~nm}$ was cut off by glass filters (UVD36A and UV-33) during photoirradiation in order that the film absorbs the light homogeneously. In this condition, the photo-acid gen- 
erator absorbs light regardless of the presence of the matrix polyimide. The mechanism of the reaction of the epoxy groups catalyzed by the photochemicallygenerated acid has been suggested in Scheme 1 though the detail on the intermediates is not clear only with our experiments. ${ }^{11}$ Acids $\left(\mathrm{H}^{+}\right)$liberated by photoirradiation cause ring-opening polymerization during post-cure.

\section{Change in IR Absorption of Epoxy Group}

We studied by IR spectroscopy the influence of irradiation time, post-curing temperature, and post-curing time on the photochemical crosslinking of PI(6FDA/ ep-AHHFP) with DIAS as photo-acid generator, and compared them to the results with DPI-AsF $F_{6}$. During the post-cure after photoirradiation, the absorbance at $905 \mathrm{~cm}^{-1}$ characteristic to the cyclic ether structure decreased as already shown in the previous paper, ${ }^{11}$ indicating the occurrence of acid-catalyzed ring opening. ${ }^{19-22}$ An absorption band at $1510 \mathrm{~cm}^{-1}$ of the aromatic ring was chosen as an internal standard since its intensity is regarded as almost constant during crosslinking reactions.

Figures 3 and 4 show decrease in epoxy group concentration versus time during post-cure at various temperatures $\left(50-195^{\circ} \mathrm{C}\right)$ with $2.5 \mathrm{~min}$ and $5 \mathrm{~min}$ irradiation, respectively. The films were irradiated with incident light intensity of $2.72 \times 10^{-9}$ einstein $\mathrm{cm}^{-2} \mathrm{~s}^{-1}$

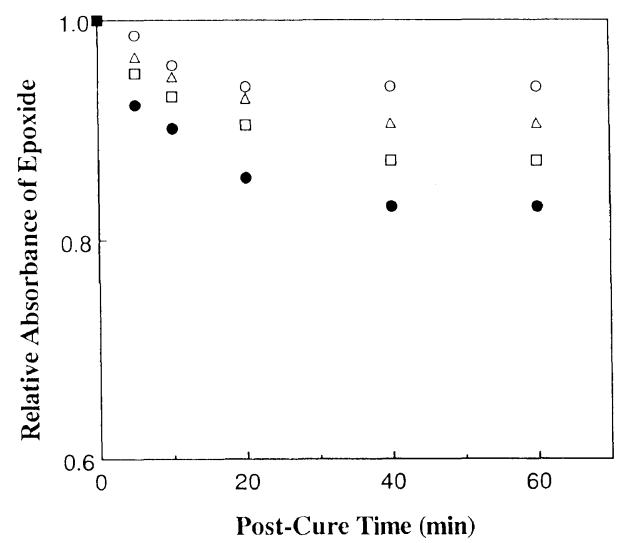

Figure 3. Changes in residual fractional concentrations of epoxy groups by photoirradiation $(2.5 \mathrm{~min})$ at various post-cure temperatures in the presence of $2.5 \mathrm{wt} \%$ DIAS. Post-cure temperature: $50(\bigcirc), 100$ $(\triangle), 150(\square)$, and $195^{\circ} \mathrm{C}$

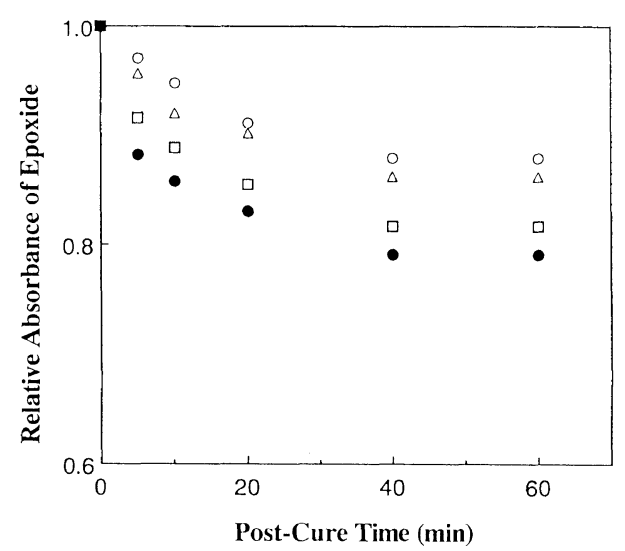

Figure 4. Changes in residual fractional concentrations of epoxy groups by photoirradiation $(5.0 \mathrm{~min})$ at various post-cure temperature in the presence of $2.5 \mathrm{wt} \%$ DIAS. Post-cure temperature: $50(\bigcirc), 100$ $(\triangle), 150(\square)$, and $195^{\circ} \mathrm{C}(\bigcirc)$. and postbaked at given temperature for given times. The epoxy group reacted quickly at the beginning of the post-cure followed by a slower rate. Figures 3 and 4 show that conversion reaches some saturation point at about $40 \mathrm{~min}$ of post-cure. A considerable number of epoxy groups remains in the polymer film due to the limited mobility of these groups in the crosslinked matrix.

Figure 5 shows a comparison of conversions at the same incident photointensity for the case of DIAS and $\mathrm{DPI}-\mathrm{AsF}_{6}$ as photo-acid generators. The photoirradiation time to obtain almost the same conversion was $5 \mathrm{~min}$

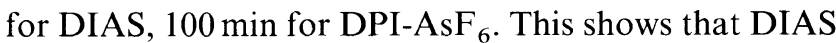
has about 20 times better efficiency than DPI-AsF $F_{6}$. However, these results considerably deviate from our expectation that the reactivity with DIAS would be much higher than that with DPI-AsF ${ }_{6}$ based simply on the difference in absorption coefficients. The reason may be differences in the nature of the photo-generated acids. Particularly, the influence of the type and size of the counter ion would be important, as it determines the type of acid formed after the photoirradiation. The molecular size of the photo-generated acid may govern the migration range of the acid in the polymer matrix.

On the basis of Figures 3 and 4, we can obtain Figure 6 that shows the saturation points of the reaction for various post-cure temperatures. The epoxy polymerization leading to crosslinking occurs as a result of photo-generation of protons within the exposed area of

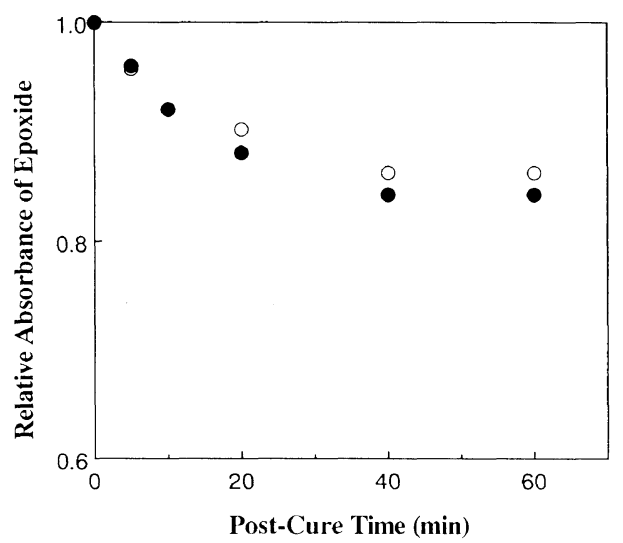

Figure 5. Comparison of conversion using DIAS $(\bigcirc, 5 \mathrm{~min}$ of irradiation time) and DPI-AsF $\mathrm{DF}_{6}(\mathcal{O}, 100 \mathrm{~min}$ of irradiation time $)$ as photo-acid generator at same incident energy $\left(2.72 \times 10^{-9}\right.$ einstein $\left.\mathrm{cm}^{-2} \mathrm{~s}^{-1}\right)$ and same post-cure temperature $\left(100^{\circ} \mathrm{C}\right)$.

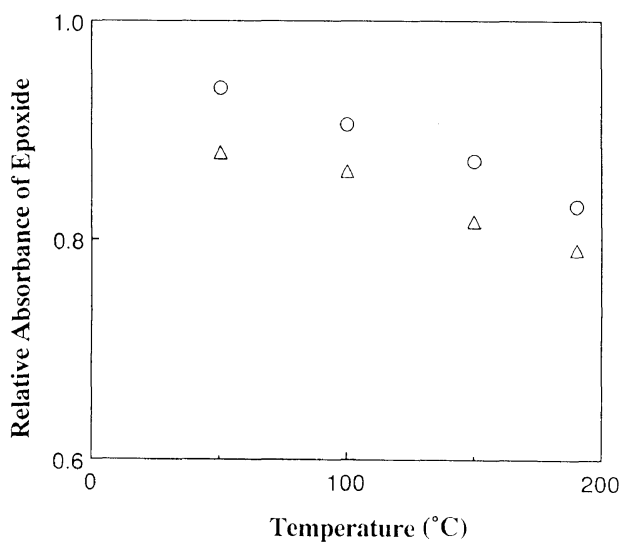

Figure 6. Effects of post-cure temperature on conversion at which reaction is saturated. Photoirradiation time: $2.5 \mathrm{~min}(\bigcirc)$ and $5 \mathrm{~min}(\triangle)$. 
the polymer film. The protons catalyze the crosslinking reaction that occurs only when thermal activation is provided by heating in the post-exposure bake step. As the temperature rises, a shorter irradiation time is sufficient to reach to the same conversion. Consequently, higher post-cure temperatures results in higher conversion.

The rate of polymerization during post-cure, $R_{\mathrm{p}}$, is related to its rate constant, $k_{\mathrm{p}}$, by eq $1,{ }^{23}$

$$
R_{\mathrm{p}}=-\mathrm{d}[\mathrm{M}] / \mathrm{d} t=k_{\mathrm{p}}[\mathrm{M}]\left[\mathrm{H}^{+}\right]
$$

where $[\mathrm{M}]$ is the concentration of the epoxy groups with its initial values, $[\mathrm{M}]_{0}=3.23 \mathrm{~mol} \mathrm{~L}^{-1}$, and $\left[\mathrm{H}^{+}\right]$is the concentration of photo-generated acid. The rate of polymerization, $R_{\mathrm{p}}$, was calculated from the initial slope of the absorbance change in IR spectra. The photogenerated acid concentration, $\left[\mathrm{H}^{+}\right]$, in film was calculated from the initial DIAS concentration $\left([\mathrm{DIAS}]_{0}=\right.$ $0.056 \mathrm{~mol} \mathrm{~L}^{-1}$ ) based on film density $=1.43$, number of absorbed photons, and quantum yield for proton formation of DIAS $\left(\Phi_{\text {acid }}=0.10\right)$. We obtained the photogenerated acid concentration, $\left[\mathrm{H}^{+}\right]$, of $0.012 \mathrm{~mol} \mathrm{~L}^{-1}$ for $2.5 \mathrm{~min}$ of photoirradiation and $0.022 \mathrm{~mol} \mathrm{~L}^{-1}$ for $5 \mathrm{~min}$ of photoirradiation. Then we can get the value of $k_{\mathrm{p}}$ from eq 1 by using the value of $R_{\mathrm{p}},[\mathrm{M}]_{0}$, and $\left[\mathrm{H}^{+}\right]$.

Arrhenius plots of $\ln k_{\mathrm{p}}$ against the inverse post-cure temperature, $1 / T$, are shown in Figure 7. The activation energy for epoxy polymerization of PI(6FDA/epAHHFP) with DIAS was calculated to be about 14 $\mathrm{kJ} \mathrm{mol}^{-1}$. Activation energy of PI(6FDA/ep-AHHFP) with $\mathrm{DPI}-\mathrm{AsF}_{6}$ for a photoinitiated cationic polymerization of epoxides was reported as $6 \mathrm{k} \mathrm{J} \mathrm{mol}^{-1}$ in our previous paper. ${ }^{11}$ The value for DIAS is larger that for DPI-AsF $F_{6}$, which would be due to differences in the type and size of counter ions of acids that are photo-generated from DIAS and DPI-AsF 6 .

The kinetic chain length, $v=\left([\mathrm{M}]_{0}-[\mathrm{M}]\right) /\left[\mathrm{H}^{+}\right]$, number of the epoxy group opened per one acid photo-generated from DIAS at various post-cure time and temperature, as well as reaction volume, $V_{\mathrm{R}}$, and reaction radius, $r_{R}$, per one photo-generated acid are listed in Table I. The value of $v$ is about $4-31$ in the present case with DIAS compared to $58-214$ for the previous case $^{11}$ with DPI-AsF 6 . As mentioned above, this difference may be due to differences in the photo-

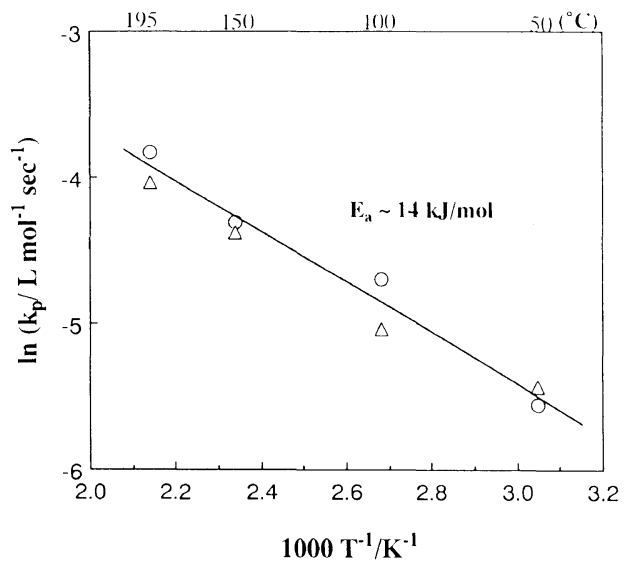

Figure 7. Arrhenius plots of initial rate constant, $k_{\mathrm{p}}$, for epoxy polymerization $v s$. post-curing temperature. Photoirradiation time: 2.5 $\min (\bigcirc)$ and $5 \min (\triangle)$ generated acid, especially its size. The reaction radius, $r_{\mathrm{R}}$, per one acid in PI(6FDA/ep-AHHFP) with DIAS is about $8-16 \AA$ when heated for $5-40 \mathrm{~min}$ at $50-$ $195^{\circ} \mathrm{C}$, which is about half that with DPI-AsF 6 .

From these results, it can be said that mobility in PI(6FDA/ep-AHHFP) of $\mathrm{AsF}_{6}{ }^{-}$, a counter anion of the acid photo-generated from the DPI-AsF $\mathrm{F}_{6}$, is higher than the mobility of 9,10-dimethoxyanthracene-2-sulfonate anion from DIAS. These results show interesting fundamental behavior of an acid in the solid state of resist materials incorporating a chemical amplification process accompanied with crosslinking reactions.

\section{Characteristic Properties as a Photosensitive Polyimide}

Figure 8 shows a typical sensitivity curve of the PI(6FDA/ep-AHHFP) containing $5.0 \mathrm{wt} \%$ of DIAS. The exposed area of the film became insoluble in the developer (cyclohexanone) after photoirradiation followed by post-cure $\left(100^{\circ} \mathrm{C}, 30 \mathrm{~min}\right)$. The normalized film thickness is plotted versus irradiated dose. The gel dose defined as the dose to give $50 \%$ of the initial thickness in the exposed regions, $D_{0 \text { gel }}$, was calculated and is shown in Figure 8 . The slope of rise in the sensitivity curve, $\tan \theta$, gives the contrast, $\gamma$, a measure of sharpness in the solubility difference between the exposed and unexposed regions.

We obtained $D_{0 \text { gel }}$ of about $117 \mathrm{~m} \mathrm{~J} \mathrm{~cm}^{-2}$ or $8.50 \times$ $10^{-8}$ einstein $\mathrm{cm}^{-2}$ based on incident energy. In our previ-

Table I. Calculated kinetic chain length, $v$, reaction volume,

$V_{\mathrm{R}}$, and reaction radius, $r_{\mathrm{R}}$, per one photo-generated acid

for post-cure of PI(6FDA/ep-AHHFP) with $2.5 \mathrm{wt} \%$ DIAS

\begin{tabular}{cccc} 
& & \multicolumn{2}{c}{ Post curing time } \\
\cline { 2 - 3 } Post curing temp & $5 \mathrm{~min}$ & $40 \mathrm{~min}$ \\
& $v$ & 4.3 & 17.6 \\
$50^{\circ} \mathrm{C}$ & $V_{\mathbf{R}} / \AA^{3}$ & $2.22 \times 10^{3}$ & $9.07 \times 10^{3}$ \\
& $r_{\mathrm{R}} / \AA$ & 8.1 & 12.9 \\
& $v$ & 6.4 & 20.4 \\
$100^{\circ} \mathrm{C}$ & $V_{\mathbf{R}} / \AA^{3}$ & $3.30 \times 10^{3}$ & $1.05 \times 10^{4}$ \\
& $r_{\mathrm{R}} / \AA$ & 9.2 & 13.6 \\
& $v$ & 12.2 & 26.5 \\
$150^{\circ} \mathrm{C}$ & $V_{\mathbf{R}} / \AA^{3}$ & $6.19 \times 10^{3}$ & $1.37 \times 10^{4}$ \\
& $r_{\mathrm{R}} / \AA$ & 11.4 & 14.8 \\
& $v$ & 20.9 & 30.9 \\
$195^{\circ} \mathrm{C}$ & $V_{\mathbf{R}} / \AA^{3}$ & $1.08 \times 10^{4}$ & $1.59 \times 10^{4}$ \\
& $r_{\mathrm{R}} / \AA$ & 13.7 & 15.6 \\
& & &
\end{tabular}

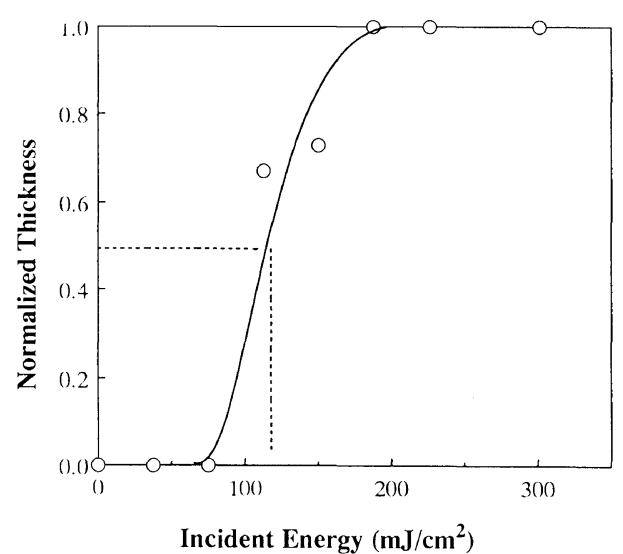

Figure 8. Characteristic curve for $\mathrm{PI}(6 \mathrm{FDA} / \mathrm{ep}-\mathrm{AHHFP})$ in the presence of $5 \mathrm{wt} \%$ DIAS with post-cure at $100^{\circ} \mathrm{C}$ for $30 \mathrm{~min} . D_{0 \mathrm{gel}}=$ $117 \mathrm{~m} \mathrm{~J} \mathrm{~cm}^{-2}$, (or $8.5 \times 10^{-8}$ einstein $\left.\mathrm{cm}^{-2}\right) ; t_{\mathrm{gel}}=31 \mathrm{~s} ; \gamma(\tan \theta)=4.0$. 
ous paper, ${ }^{11}$ we obtained $D_{0 \text { gel }}$ of $1.52 \times 10^{-6}$ einstein $\mathrm{cm}^{-2}$ based on incident energy using $5 \mathrm{wt} \%$ DPIAs- $\mathrm{F}_{6}$. It can be simply said that DIAS needs incident energy for gelation about eighteen times less than that for DPI$\mathrm{AsF}_{6}$. This agrees well with that derived from epoxide consumption in Figure 5. The value of $\gamma$ is 4.0 in the present case.

The quantum yield for crosslinking, $\Phi_{\text {gel }}$, can be determined from the gel dose, $D_{\text {ogel }}$, by using eq $2,{ }^{24}$

$$
\Phi_{\mathrm{gel}}=l d /\left(M_{\mathrm{w} 0} A D_{\mathrm{ogel}}\right)=l d /\left(M_{\mathrm{w} 0} I_{\mathrm{abs}} t_{\mathrm{gel}}\right)
$$

where $M_{\mathrm{w} 0}$ is the weight-average molecular weight before photoirradiation, $A$ is the absorption efficiency, $I_{\text {abs }}$ is the rate of radiation absorption, $t_{\text {gel }}$ is the gel time calculated from the characteristic curve, $l$ is the film thickness, and $d$ is the density. We calculated the gelation time, $t_{\mathrm{gel}}$, to be $31 \mathrm{~s}$ and the rate of radiation absorption, $I_{\text {abs }}$, to be $5.53 \times 10^{-10}$ einstein $\mathrm{cm}^{-2} \mathrm{~s}^{-1}$. By these values together with $M_{\mathrm{w} 0}=99,300$, average film thickness, $l=1.0 \mu \mathrm{m}$, and density, $d=1.43$, the quantum yield for crosslinking of PI(6FDA/ep-AHHFP), $\Phi_{\text {gel }}$, was calculated to be about 0.084 . Using the initiation quantum yield of 0.1 for acid generation, the number of crosslinks per one photo-generated acid would become about 0.84 for the present system. Compared to the results with $\operatorname{DPI}_{-A s F_{6}}\left(\Phi_{\mathrm{gel}} \sim 3.0\right)$, the value with DIAS is very small probably due to differences in mobility of the acids in PI(6FDA/ep-AHHFP) as mentioned above.

The absorption efficiency, $\mathrm{A}$, is much improved to be 0.20 in the present case with DIAS in contrast to $A=3.1 \times 10^{-4}$ for the previous case of $\mathrm{DPI}_{-\mathrm{AsF}_{6}}$. It is noteworthy that the gelation time of $t_{\mathrm{gel}}=31 \mathrm{~s}$ with post-cure at $100^{\circ} \mathrm{C}$ for $30 \mathrm{~min}$ corresponds to about $3.5 \%$ conversion of epoxy group, which supports that gelation and infinite network formation in PI(6FDA/ep-AHHFP) films have already occurred in the very early stage of post-cure reactions in Figures 3 and 4.

\section{CONCLUSION}

Photochemical reactivity of PI(6FDA/ep-AHHFP) was studied in the presence of DIAS as a photo-acid generator. IR spectroscopy was used for detecting post-cure reactions. Using DIAS, the irradiation time was shortened by twenty times for getting the same conversion compared to the case of DPI-AsF $\mathrm{A}_{6}$, which suggests that DIAS has twenty times better efficiency for the photocrosslinking of $\mathrm{PI}(6 \mathrm{FDA} / \mathrm{ep}-\mathrm{AHHFP})$ than DPI-AsF $F_{6}$. The activation energy for epoxy polymerization of PI(6FDA/ep-AHHFP) with DIAS is about 14 $\mathrm{kJ}$ mol $^{-1}$. The kinetic chain length, $v$, per one acid in PI(6FDA/ep-AHHFP) with DIAS was calculated to be about $4-31$. The reaction radius, $r_{R}$, per one acid was determined to be about $8-16 \AA$ when heated for 5 $40 \mathrm{~min}$ at $50-195^{\circ} \mathrm{C}$, which is about a half of the case with $\mathrm{DPI}-\mathrm{AsF}_{6}$. It can be said from these results that the mobility of 9,10-dimethoxyanthracene-2-sulfonate anion, photo-generated from DIAS is lower than the mobility of $\mathrm{AsF}_{6}{ }^{-}$formed from the DPI-AsF 6 . The quantum yield for crosslinking of PI(6FDA/epAHHFP), $\Phi_{\text {gel }}$, was obtained to be about 0.084 from the characteristic curve. The gel dose, $D_{0 \text { gel }}$, and contrast, $\gamma$, after post-cure at $100^{\circ} \mathrm{C}$ for $30 \mathrm{~min}$ are $117 \mathrm{~m} \mathrm{~J} \mathrm{~cm}^{-2}$ or $8.50 \times 10^{-8}$ einstein $\mathrm{cm}^{-2}$ and 4.0 , respectively. PI(6FDA/ep-AHHFP) containing DIAS was ascertained to work as a negative-tone photosensitive polyimide.

\section{REFERENCES}

1. R. Rubner, H. Ahne, E. Kuhn, and G. Kolodziej, Photogr. Sci. Eng., 23, 303 (1979).

2. J. Pfeifer and O. Rohde, "Proceedings of 2nd International Conference Polyimides," Society of Plastics Engineers, Inc., New York, N.Y., 1985, p 130

3. N. Yoda and H. Hiramoto, J. Macromol. Sci. Chem., A21, 1641 (1984).

4. K. Horie and T. Yamashita eds., "Photosensitive Polyimides, Fundamentals and Applications," Technomic Publishing Co., Inc., Lancaster, Penn., 1995.

5. R. Rubner, Adv. Mater., 2 (10), 452 (1990).

6. H. Higuchi, T. Yamashita, K. Horie, and I. Mita, Chem. Mater., 3 (1), 188 (1991).

7. T. Yamashita and K. Horie, in a "Polymers in Microlithography"; American Chemical Society symposium series No. 537, L. F. Thompson, C. G. Willson, and S. Tagawa, Ed., American Chemical Society, Washington, D.C., 1994, 440.

8. Q. Jin, T. Yamashita, and K. Horie, J. Polym. Sci., Part A, Polym. Chem., 32, 503 (1994).

9. H. Ito and C. G. Willson, "Technical Papers of SPE Regional Technical Conference on Photopolymers," Society of Plastics Engineers, Inc., New York, N.Y., 1982, p 331.

10. J. M. J. Frechet, H. Ito, and C. G. Willson, Proc. Microcircuit Eng., 260 (1982).

11. H. S. Yu, T. Yamashita, and K. Horie, Macromolecules, in press.

12. J. V. Crivello and J. H. W. Lam, J. Polym. Sci., Part A, Polym. Chem., 16, 2441 (1978).

13. S. P. Pappas, L. R. Gatechair, and J. H. Jilek, J. Polym. Sci., Part A, Polym. Chem., 22, 77 (1984).

14. G. Manivannan and J. P. Fouassier, J. Polym. Sci., Part A, Polym. Chem., 29, 1113 (1991).

15. H. S. Yu, T. Yamashita, and K. Horie, J. Photopolym. Sci. Technol, 8 (2), 269 (1995).

16. K. Naitoh, T. Yamaoka, and A. Umehara, Chem. Lett., 1869 (1991).

17. D. R. Mckean, U. Schaedeli, and S. A. Macdonald, J. Polym. Sci., Part A, Polym. Chem., 27, 3927 (1989).

18. K. Naitoh, K. Ishii, T. Yamaoka, and T. Omote, J. Photopolym. Sci., Technol., 5 (2), 339 (1992).

19. C. Decker and K. Moussa, Makromol. Chem., 189, 2381 (1988).

20. A. Udagawa, F. Sakurai, and T. Takahashi, J. Appl. Polym. Sci., 42, 1861 (1991).

21. K. Naitoh, K. Koseki, and T. Yamaoka, J. Appl. Polym. Sci., 50, 243 (1993).

22. D. Wang, L. Carrera, and M. J. M. Abadie, Eur. Polym. J., 29 (10), 1379 (1993)

23. C. Decker and K. Moussa, J. Polym. Sci., Part A, Polym. Chem., 28, 3429 (1990).

24. R. Rubner, H. Ahne, E. Kuhn, and G. Kolodziej, Photogr. Sci. Eng., 20 (5), 225 (1976). 